\title{
Prevalence of urinary tract infection among children
}

\author{
Moatez Almofarreh ${ }^{1 *}$, Zainab Alowaa ${ }^{2}$, Elaf Junainah ${ }^{3}$, Nourah Alshahrani ${ }^{4}$, Meshal Alharbi ${ }^{5}$, \\ Waleed Alkhalifah ${ }^{5}$, Amer Aldmak ${ }^{5}$, Mohammed Salawi ${ }^{6}$, Abdullah Alaradi ${ }^{7}$, Ruya Althomali ${ }^{8}$
}

\author{
${ }^{1}$ Department of Medicine, Aljouf University, Aljouf, Saudi Arabia \\ ${ }^{2}$ Department of Internal Medicine, Dhahran General Hospital, Dhahran, Saudi Arabia \\ ${ }^{3}$ Department of Pediatrics, King Abdulaziz Hospital, Jeddah, Saudi Arabia \\ ${ }^{4}$ Department of Medicine, King Khalid University, Abha, Saudi Arabia \\ ${ }^{5}$ Department of Medicine, Qassim University, Qassim, Saudi Arabia \\ ${ }^{6}$ Department of Medicine, Jazan University, Jazan, Saudi Arabia \\ ${ }^{7}$ Department of Medicine, Imam Abdulrahman Bin Faisal University, Dammam, Saudi Arabia \\ ${ }^{8}$ Department of Medicine, Taif University, Taif, Saudi Arabia
}

Received: 04 September 2018

Accepted: 08 September 2018

\author{
*Correspondence: \\ Dr. Moatez Almofarreh, \\ E-mail: mkmf2025@gmail.com
}

Copyright: (c) the author(s), publisher and licensee Medip Academy. This is an open-access article distributed under the terms of the Creative Commons Attribution Non-Commercial License, which permits unrestricted non-commercial use, distribution, and reproduction in any medium, provided the original work is properly cited.

\begin{abstract}
Urinary tract infection is the third most common cause of febrile illness among children. UTI carries a considerable morbidity among this vulnerable age group because of its potential complications (e.g. hypertension and renal failure). Because diagnosis of UTI among the pediatric age group is challenging if solely based on clinical setting, knowledge of the actual prevalence rates of UTI among children is essential for pediatricians to determine the cost benefit effect of requesting investigations for suspected cases. Infants and children with UTI often present with fever with or without urinary symptoms. During assessment of a febrile child, pediatricians should be aware of the prevalence and risk factors for UTI in febrile children that necessitate further investigations. Prevalence of UTI among children is highly variable among different studies and the variability is attributed to multiple factors. This article aims at reviewing the prevalence of UTI in children reported among various literature studies and discussing factors influencing this prevalence.
\end{abstract}

Keywords: Children, Prevalence, UTI

\section{INTRODUCTION}

Urinary tract infection (UTI) is a significant health problem that commonly affects children. ${ }^{1}$ It is estimated to be the third most common cause of fever in children after gastrointestinal infections and respiratory diseases. ${ }^{2}$ UTI at this critical and vulnerable age group is associated with considerable morbidity because it can lead to serious complications such as hypertension, renal scarring, and end-stage renal failure. ${ }^{3}$ Clinically, children with acute pyelonephritis often present with high fever, abdomino- pelvic pain, and urinary symptoms. However, these symptoms are not specific and they may occur in lower urinary tract infections such as cystitis. ${ }^{4}$ On clinical basis, the differentiation between both conditions is challenging. Therefore, further investigations are required to determine the accurate diagnosis and prognosis. ${ }^{2}$

The prevalence of UTI among children is variable in literature, and many predisposing factors are known to increase the risk of this condition among this age group. These factors are either intrinsic related to the integrity of 
the immune system and the urological organs, or extrinsic predisposing the child to pathogenic organisms. Intrinsic factors include immune deficiency states, immunoglobulin A levels in urine, and blood group antigens types. Extrinsic risk factors include constipation, non-circumcision in boys, obstructive uropathy, and urolithiasis. $^{5}$

The aim of this article is to review the prevalence of UTI reported among children in various literature studies and to discuss the factors that influence the prevalence rates among the pediatric age group.

\section{INCIDENCE AND PREVALENCE OF UTI IN CHILDREN}

Urinary tract infection is the third most common cause of febrile illness among pediatric age group, and it accounts for $0.7 \%$ of all outpatients' clinic visits. ${ }^{1}$ In Emergency Department, up to $14 \%$ of children are admitted due to UTI either due to direct infection or indirectly due to its associated complications. ${ }^{6}$ Knowledge of the exact incidence and prevalence of UTI among children is essential for pediatricians because the diagnosis of the diagnosis may be challenging on clinical basis, and the incidence and prevalence will determine the cost benefit effect of investigating the condition. For instance, if UTI was rare, routine diagnostic testing would not be beneficial, whilst if it was common, pediatricians will be justified to use lab and imaging investigations for screening the suspected cases.

The prevalence of UTI was, therefore, a subject of interest of many researchers. Partly for the difficulty in clinical diagnosis and partly due to the grave potential complications associated with pyelonephritis such as hypertension and end-stage renal failure. Unfortunately, many limitations existed and still exist in estimation of the exact prevalence of UTI among children. First, the child or infant cannot communicate or identify the symptoms of UTI and therefore doesn't seek medical advice except when fever, significant abdominal pain, or pyuria occur. Second, definite clinical criteria for confirmation or exclusion of UTI are still lacking. Third, most of the literature studies could not differentiate between cystitis and pyelonephritis when exploring the UTI prevalence among children. Thus, the reported prevalence rates are considerably variable, inconsistent, and poorly representative.

Overall, the prevalence of UTI among febrile infants and young children is estimated to be approximately $4-7 \%{ }^{7}$ However, it varies according to the age, sex, race, nutritional state, the state of circumcision, and the other factors as well mentioned in next sections. The prevalence also seems to be increasing over time. The average prevalence of UTI among children reported by the American Academy of Pediatrics in 1999 was 5\%. Shaikh et al, in their metanalysis in 2008 , reported an average prevalence rate of $7 \%$ among febrile children below 2 years of age. ${ }^{1}$ The prevalence rate varied between 5.5 to 8.1 among the studies. ${ }^{9,10}$

Many factors were reported to affect the prevalence of UTI among children. Gender is one of the most common factors affecting the UTI prevalence rates. Females were reported to have a higher prevalence rates of UTI in comparison to men particularly during the first 12 months of life. ${ }^{10-12}$ The prevalence among females during the first year of life was reported to be as high as $13.6 \%$ of febrile infants. ${ }^{13}$ Later on, the prevalence of UTI among females decreased to become equal or slightly lower than male children. ${ }^{13-15}$ The significant difference encountered among both genders may be attributed to the different anatomical structure of the urethra between males and females. The straight exposed urethra in young female infants is vulnerable to transmitted infection in comparison to the tortious protected urethra of males. With age progression, other risk factors may play a role in increased prevalence of UTI among males such as the uncircumcision.

The circumcision state is the second determining factor for the prevalence of UTI among children. Authors reported a significant difference UTI prevalence between circumcised and uncircumcised males. At the age of 3 months, the prevalence of UTI among uncircumcised boys was reported to be as high as $20.1 \%$ of febrile infants, whilst rates as low as $0.3 \%$ were reported among circumcised boys at the same age. ${ }^{9,13}$ This is specifically important for pediatricians to consider the necessity to catheterize all uncircumcised male infants below the age of 3 months presenting to their offices or hospitals with fever.

As regards to the age, the prevalence of UTI was reported to decrease over time with age progression in both males and females. The highest prevalence of UTI occurs during the first month of life with values ranging from 8.6 to $11.6 \% .^{1,16}$ These numbers drop significantly between the age of 6 and 12 months to reach values ranging from 0.3 to $7.3 \%$ in circumcised and uncircumcised male infants, consequently. ${ }^{9,17}$ After the age of 1 year, the prevalence was reported to be as low as 2.1-4.1\%. ${ }^{9}$ In comparison with adults, the differences are considerable. For instance, whereas the prevalence of UTI among female children was reported to be around $7.8 \%$, the prevalence among adult females was reported to be as high as $50 \%{ }^{5,18}$ This may be attribute to the hormonal changes and sexual activating among adults. However, the relatively low prevalence among children may probably be due to the inability to communicate their symptoms in comparison to the well-educated adults.

Race also was reported to affect the prevalence of UTI among children. White American children have higher prevalence of UTI in comparison to African American children. However, the etiology of this difference is still unknown. ${ }^{1}$ 
Malnutrition is another risk factor for UTI among children. UTI prevalence is significantly higher among malnourished children in comparison to their wellnourished counterparts. Nuwaezuke, in his review of 13 studies exploring the prevalence of UTIC among children, reported that the prevalence of UTI among malnourished children ranged from $8 \%$ to $37 \% .19$ Adequate nutrition is fundamental for the integrity of the immune system, and therefore, it is essential for guarding against infection. ${ }^{20}$ Children with severe malnutrition such as marasmus or kwashiorkor have a high prevalence of UTI. ${ }^{21,22}$ Children with complicated malnutrition, such as those case associated with lethargy, hypothermia, and hypoglycemia, have higher risk for developing UTI. ${ }^{23}$

Many other factors are well-established risk factors for UTI in children. These factors include urolithiasis, bladder dysfunction with incomplete emptying, vesicoureteric reflux, obstructive uropathy, constipation, excessive immunoglobulin A excretion in urine, and others. ${ }^{4,5}$ However, data are lacking about the influence of these factors on the prevalence of UTI among the pediatric age group.

\section{CONCLUSION}

UTI is a common condition among infants and young children. The prevalence is variable among different studies and is affected by multiple factors. Overall, the average prevalence is about $7 \%$ among febrile children. Age, sex, race, circumcision state, and nutritional state are the main determinant of UTI among children. UTI is more common among females, uncircumcised males, White American children, infants below the age of 3 months, and infants with severe malnutrition. Other factors that increase the risk for UTI include urolithiasis, bladder dysfunction with incomplete emptying, vesicoureteric reflux, obstructive uropathy, constipation, and excessive immunoglobulin A excretion in urine. However, data are lacking about the influence of these factors on the prevalence of UTI among the pediatric age group.

\section{Funding: No funding sources \\ Conflict of interest: None declared \\ Ethical approval: Not required}

\section{REFERENCES}

1. Shaikh N, Morone NE, Bost JE, Farrell MH. Prevalence of urinary tract infection in childhood: a meta-analysis. Pediatr Infect Dis J. 2008;27(4):3028 .

2. Roberts KB. Urinary tract infection: clinical practice guideline for the diagnosis and management of the initial UTI in febrile infants and children 2 to 24 months. Pediatr. 2011;128(3):595-610.

3. The Korean Society of Infectious Diseases and Korean Society for Chemotherapy. Clinical guideline for the diagnosis and treatment of urinary tract infections: Asymptomatic bacteriuria, uncomplicated and complicated urinary tract infections, bacterial prostatitis. Infect Chemother. 2011;43(1):1-25.

4. Chang SL, Shortliffe LD. Pediatric urinary tract infections. Pediatr Clin North Am. 2006;53(3):379400.

5. Roberts JA. Factors predisposing to urinary tract infections in children. Pediatr Nephrol. 1996;10(4):517-22.

6. Freedman AL. Urologic diseases in North America project: Trends in resource utilization for urinary tract infections in children. J Urol. 2005;173:94954.

7. O'Brien K, Stanton N, Edwards A, Hood K, Butler CC. Prevalence of urinary tract infection (UTI) in sequential acutely unwell children presenting in primary care: Exploratory study. Scand J Prim Health Care. 2011;29(1):19-22.

8. Finnell SME, Carroll AE, Downs SM, Subcommittee on Urinary Tract Infection. Technical report-diagnosis and management of an initial uti in febrile infants and young children. Pediatr. 2011;128(3):e749-70.

9. Bachur R, Harper MB. Reliability of the urinalysis for predicting urinary tract infections in young febrile children. Arch Pediatr Adolesc Med. 2001;155(1):60-5.

10. Shaw KN, Gorelick M, McGowan KL, Yakscoe NM, Schwartz JS. Prevalence of urinary tract infection in febrile young children in the emergency department. Pediatr. 1998;102(2):e16.

11. Newman TB, Bernzweig JA, Takayama JI, Finch SA, Wasserman RC, Pantell RH. Urine testing and urinary tract infections in febrile infants seen in office settings. Arch Pediatr Adolesc Med. 2002;156(1):44.

12. Zorc JJ, Levine DA, Platt SL. Clinical and demographic factors associated with urinary tract infection in young febrile infants. Pediatr. 2005;116(3):644-8.

13. Lin DS, Huang SH, Lin CC. Urinary tract infection in febrile infants younger than eight weeks of age. Pediatr. 2000;105(2):E20.

14. Crain EF, Gershel JC. Urinary tract infections in febrile infants younger than 8 weeks of age. Pediatr. 1990;86(3):363-7.

15. Krober MS, Bass JW, Powell JM, Smith FR, Seto DS. Bacterial and viral pathogens causing fever in infants less than 3 months old. Am J Dis Child. 1985;139(9):889-92.

16. Jakobsson B, Esbjörner E, Hansson S. Minimum incidence and diagnostic rate of first urinary tract infection. Pediatrics. 1999;104(2)(1):222-6.

17. Hoberman A, Chao HP, Keller DM, Hickey R, Davis HW, Ellis D. Prevalence of urinary tract infection in febrile infants. $J$ Pediatr. 1993;123(1):17-23.

18. Bent S, Nallamothu BK, Simel DL, Fihn SD, Saint $\mathrm{S}$. Does this woman have an acute uncomplicated 
urinary tract infection? JAMA. 2002;287(20):270110.

19. Uwaezuoke SN. The prevalence of urinary tract infection in children with severe acute malnutrition: a narrative review. Pediatr Heal Med Ther. 2016;7:121-7.

20. Iyer SS, Chatraw JH, Tan WG. Protein energy malnutrition impairs homeostatic proliferation of memory CD8 T cells. J Immunol. 2012;188(1):7784.

21. Rabasa AI, Shattima D. Urinary tract infection in severely malnourished children at the University of Maiduguri Teaching Hospital. J Trop Pediatr. 2002;48(6):359-61.
22. Page AL, de Rekeneire N, Sayadi S. Infections in children admitted with complicated severe acute malnutrition in Niger. PLoS One. 2013;8(7):e68699.

23. Shimeles D, Lulseged S. Clinical profile and pattern of infection in Ethiopian children with severe protein-energy malnutrition. East Afr Med J. 1994;71(4):264-7.

Cite this article as: Almofarreh M, Alowaa Z, Junainah E, Alshahrani N, Alharbi M, Alkhalifah W, et al. Prevalence of urinary tract infection among children. Int J Contemp Pediatr 2018;5:2356-9. 